\title{
Fluorescence spectroscopy: a rapid tool for assessing tetracycline resistance in Bifidobacterium longum
}

\author{
Mohammed Salim Ammor, Ana Belén Flórez, Abelardo Margolles, and Baltasar Mayo
}

\begin{abstract}
The tetracycline uptake kinetics of 35 Bifidobacterium longum strains isolated from the human gastrointestinal tract were examined by fluorescence spectroscopy, and the suitability of the technique as a screening tool of tetracycline resistance or susceptibility was determined. The strains were first grouped into three classes based on their corresponding minimum inhibitory concentrations (MICs) of tetracycline, as established by the microdilution method: susceptible (MICs $\leq 1 \mu \mathrm{g} \mathrm{mL}^{-1}$ ), semi-resistant (MICs between 1 and $\leq 32 \mu \mathrm{g} \mathrm{mL}^{-1}$ ), and resistant strains $(\mathrm{MICs} \geq 32 \mu \mathrm{g} \mathrm{mL}-1$ ). The kinetics of tetracycline uptake for the strains in each resistance group were then analyzed over a 20 min period by fluorescence spectroscopy (absorbance wavelength $524 \mathrm{~nm}$, excitation wavelength $400 \mathrm{~nm}$ ) in a buffer system containing $100 \mu \mathrm{g} \mathrm{mL}^{-1}$ tetracycline. Principal component analysis and factorial discriminant analysis of the results showed excellent distinction among susceptible, semi-resistant, and resistant strains. The proposed method provides a powerful and convenient means of rapidly screening tetracycline resistance in B. longum.
\end{abstract}

Key words: fluorescence spectroscopy, Bifidobacterium longum, antibiotic resistance, tetracycline uptake, multidimensional data analysis.

\begin{abstract}
Résumé : Les cinétiques d'absorption de la tétracycline chez 35 souches de Bifidobacterium longum isolées du tractus gastro-intestinal humain furent examinées par spectroscopie à fluorescence et la performance de cette technique comme outil de criblage de la résistance ou susceptibilité à la tétracycline fut déterminée. Les souches furent d'abord groupées en trois classes selon leurs concentrations inhibitrices minimales (CMI) à la tétracycline correspondantes telles que déterminées par la méthode de microdilution: souches susceptibles $\left(\mathrm{CMI} \leq 1 \mu \mathrm{g} \mathrm{mL}^{-1}\right)$, semi-resistante $(\mathrm{CMI}$ entre 1 et $\leq 32 \mu \mathrm{g} \mathrm{mL}^{-1}$ ) et résistantes $\left(\mathrm{CMI} \geq 32 \mu \mathrm{g} \mathrm{mL}^{-1}\right.$ ). Les cinétiques d'absorption de la tétracycline pour les souches dans chacun des groupes de résistance furent par la suite analysée sur une durée de 20 minutes par spectroscopie à fluorescence (longueur d'onde d'absorbance de $524 \mathrm{~nm}$, longueur d'onde d'excitation de $400 \mathrm{~nm}$ ) dans un système tamponné contenant $100 \mu \mathrm{g} \mathrm{mL}^{-1}$ de tétracycline. Une analyse des composantes principales et une analyse factorielle du discriminant des résultats ont démontré une excellente distinction entre les souches susceptibles, semi-résistantes et résistantes. La méthode proposée fournit un moyen performant et pratique pour cribler rapidement la résistance à la tétracycline chez B. longum.
\end{abstract}

Mots clés : spectroscopie à fluorescence, Bifidobacterium longum, résistance aux antibiotiques, absorption de la tétracycline, analyse multidimensionnelle des données.

[Traduit par la Rédaction]

\section{Introduction}

Tetracyclines were discovered in the 1940s and shown to have activity against a wide range of microorganisms, including Gram-positive and -negative bacteria, chlamydiae, mycoplasmas, rickettsiae, and even protozoan parasites (Chopra and Roberts 2001). These antibiotics have been extensively used in the prophylaxis and treatment of human and animal infections. They have also been used at the subtherapeutic

Received 6 January 2006. Revision received 24 March 2006. Accepted 27 March 2006. Published on the NRC Research Press Web site at http://cjm.nrc.ca on 29 July 2006.

M.S. Ammor, ${ }^{1}$ A.B. Flórez, A. Margolles, and B. Mayo. Instituto de Productos Lácteos de Asturias (CSIC), Carretera de Infiesto s/n, 33300 Villaviciosa, Asturias, Spain.

${ }^{1}$ Corresponding author (e-mail: ammor@ipla.csic.es). level as growth promoters in animal feeds (Wegener 2003). However, this intensive and extensive use has caused tetracycline resistance to spread to a large number of commensal, opportunistic, and pathogenic bacteria (Chopra and Roberts 2001; Roberts 2005). This resistance is mostly acquired by the horizontal transmission of genes coding for energydependent efflux systems or for proteins that protect the bacterial ribosomes from the blockage of protein synthesis (Chopra and Roberts 2001).

Bifidobacterium longum is among the dominant bifidobacterial species of the human gastrointestinal tract (GIT) (Ventura et al. 2004), where it is thought to have several health-promoting effects, including the prevention of diarrhea in antibiotic-treated patients, the reduction of cholesterol levels, the alleviation of lactose intolerance symptoms, and the stimulation of the immune system (Ouwehand et al. 2002). Given these possible properties, this species is frequently used as a probiotic in dairy products or is included 
in dietary supplements (Tuohy et al. 2003). The selection of suitable strains for this purpose is difficult, however, since the key characteristics necessary for survival and competition in the human GIT are poorly understood (O'Sullivan 2001). Nevertheless, agreement exists that the strains used in food systems should be free of potentially transferable determinants of antibiotic resistance (European Commission 2001). A few B. longum strains have already been characterized as resistant to certain antibiotics, including tetracycline (Delgado et al. 2005; Moubareck et al. 2005), and at least two tetracycline-resistant determinants in bifidobacterial species - tet $(\mathrm{W})$ and tet $(\mathrm{M})$ - have been characterized (Lacroix and Walker 1995; Scott et al. 2000). Thus, to avoid the spread of resistance via probiotics, systematic checking for antibiotic resistance (in particular to tetracycline) is essential.

The antibiotic resistance or susceptibility profiles of bifidobacteria have been assessed by many methods, e.g., disk diffusion (Matteuzzi et al. 1983; Charteris et al. 1998), agar dilution (Lim et al. 1993), microdilution (Delgado et al. 2005), and the E-test (Charteris et al. 2001). However, more robust methods would facilitate large-scale screening in the search for new industrial strains.

Tetracycline fluoresces after excitation with light of at least $400 \mathrm{~nm}$. Therefore, fluorescence spectroscopy can be used to monitor its uptake in bacterial cells, i.e., the influx of the antibiotic from the external environment to the cell interior. The aim of the present work was to use fluorescence spectroscopy to follow tetracycline uptake in strains of $B$. longum with different mean inhibitory concentrations (MICs) for this antibiotic. The results show the suitability of this technique as a screening tool of tetracycline resistance or susceptibility.

\section{Materials and methods}

\section{Strains and growth conditions}

The bacteria used in this study were 35 B. longum isolates whose tetracycline MICs are known to be different (Delgado et al. 2005) (Table 1). The B. longum type strain LMG $13197^{\mathrm{T}}$ was included as a control in all analyses.

Frozen bacteria were subcultured twice in De Man Rogosa - Sharpe (MRS) agar (Biokar Diagnostics, Beauvais, France) containing $0.25 \%$ cysteine (Sigma Chemical, St. Louis, Missouri, USA) (MRS+C) prior to performing the assays. Isolated colonies were finally added to $10 \mathrm{~mL}$ of $\mathrm{MRS}+\mathrm{C}$ broth and cultured at $37^{\circ} \mathrm{C}$ for $48 \mathrm{~h}$ in an anaerobic chamber (MAC500; Down Whitley Scientific, West Yorkshire, UK) containing an atmosphere of $85 \% \mathrm{~N}_{2}, 10 \% \mathrm{H}_{2}$, and $5 \% \mathrm{CO}_{2}$.

\section{MICs of tetracycline}

The MICs of tetracycline for the different strains were determined with the Sensititre Anaero3 commercial system (Trek Diagnostic Systems, East Grinstead, UK), following the manufacturer's recommendations. Briefly, colonies of each strain grown on solid media were used to make a 0.5 McFarland suspension in Brucella Standard broth (Trek Diagnostic Systems, Cleveland, Ohio, USA), and $100 \mu \mathrm{L}$ of this suspension was then transferred to $10 \mathrm{~mL}$ of the same medium, to which haemin and vitamin $\mathrm{K}_{1}$ (Merck, VWR,
Table 1. Mean inhibitory concentration (MIC) of tetracycline, as determined by microdilution using the Sensititre Anaero3 system.

\begin{tabular}{|c|c|}
\hline $\begin{array}{l}\text { Isolate or } \\
\text { strain }\end{array}$ & $\begin{array}{l}\text { MIC of tetracycline } \\
\left(\mu \mathrm{g} \mathrm{mL}^{-1}\right)\end{array}$ \\
\hline \multicolumn{2}{|c|}{ Susceptible strains $(\mathrm{MIC} \leq 1)$} \\
\hline $\mathrm{C} 51 *$ & $\leq 1$ \\
\hline C54 & $\leq 1$ \\
\hline C55 & $\leq 1$ \\
\hline C56 & $\leq 1$ \\
\hline $\mathrm{C} 71 *$ & $\leq 1$ \\
\hline C72 & $\leq 1$ \\
\hline C73 & $\leq 1$ \\
\hline $\mathrm{C} 62_{\mathrm{MC}}$ & $\leq 1$ \\
\hline E44 & $\leq 1$ \\
\hline L25 & $\leq 1$ \\
\hline L43* & $\leq 1$ \\
\hline $\mathrm{L} 45^{*}$ & $\leq 1$ \\
\hline L46 & $\leq 1$ \\
\hline $\mathrm{M} 21^{*}$ & $\leq 1$ \\
\hline M22 & $\leq 1$ \\
\hline M23 & $\leq 1$ \\
\hline M24 & $\leq 1$ \\
\hline M25 & $\leq 1$ \\
\hline M26 & $\leq 1$ \\
\hline M27 & $\leq 1$ \\
\hline LMG $13197^{\mathrm{T}}$ & $\leq 1$ \\
\hline \multicolumn{2}{|c|}{ Semi-resistant strains $(1<$ MIC < 32) } \\
\hline H91 & 4 \\
\hline H65 & 8 \\
\hline L41 & 8 \\
\hline B95 & 16 \\
\hline H68 & 16 \\
\hline H93 & 16 \\
\hline L42 & 16 \\
\hline L44 & 16 \\
\hline \multicolumn{2}{|c|}{ Resistant strains $($ MIC $\geq 32)$} \\
\hline E111 & 64 \\
\hline H66 & 128 \\
\hline H94 & 128 \\
\hline H67 & $\geq 256$ \\
\hline H92 & $\geq 256$ \\
\hline H95 & $\geq 256$ \\
\hline
\end{tabular}

*Test strains; all others were used to construct the model.

Darmstadt, Germany) were added (approximate final bacterial concentration $\left.1 \times 10^{6} \mathrm{cfu} \mathrm{mL}^{-1}\right)$. One hundred microlitres of this suspension was inoculated into each well of the Sensititre plates and incubated at $37{ }^{\circ} \mathrm{C}$ in anaerobic conditions for $48 \mathrm{~h}$. The growth of the strains was recorded by visual inspection.

\section{Fluorescence spectroscopy}

\section{Sample preparation}

The strains were propagated in MRS+C agar for 24-48 h. One colony was placed in $10 \mathrm{~mL}$ of $\mathrm{MRS}+\mathrm{C}$ broth and incu- 
Fig. 1. Spectra of tetracycline uptake kinetics recorded following excitation at $400 \mathrm{~nm}$ in dilute suspensions of Bifidobacterium longum L46 (solid line) $\left(\mathrm{MIC}<1 \mu \mathrm{g} \mathrm{mL}^{-1}\right)$, L42 (heavy grey line) $\left(\mathrm{MIC}=16 \mu \mathrm{g} \mathrm{mL}^{-1}\right)$, and H67 (broken line) $\left(\mathrm{MIC}^{2} 256 \mu \mathrm{g} \mathrm{mL} \mathrm{m}^{-1}\right)$.

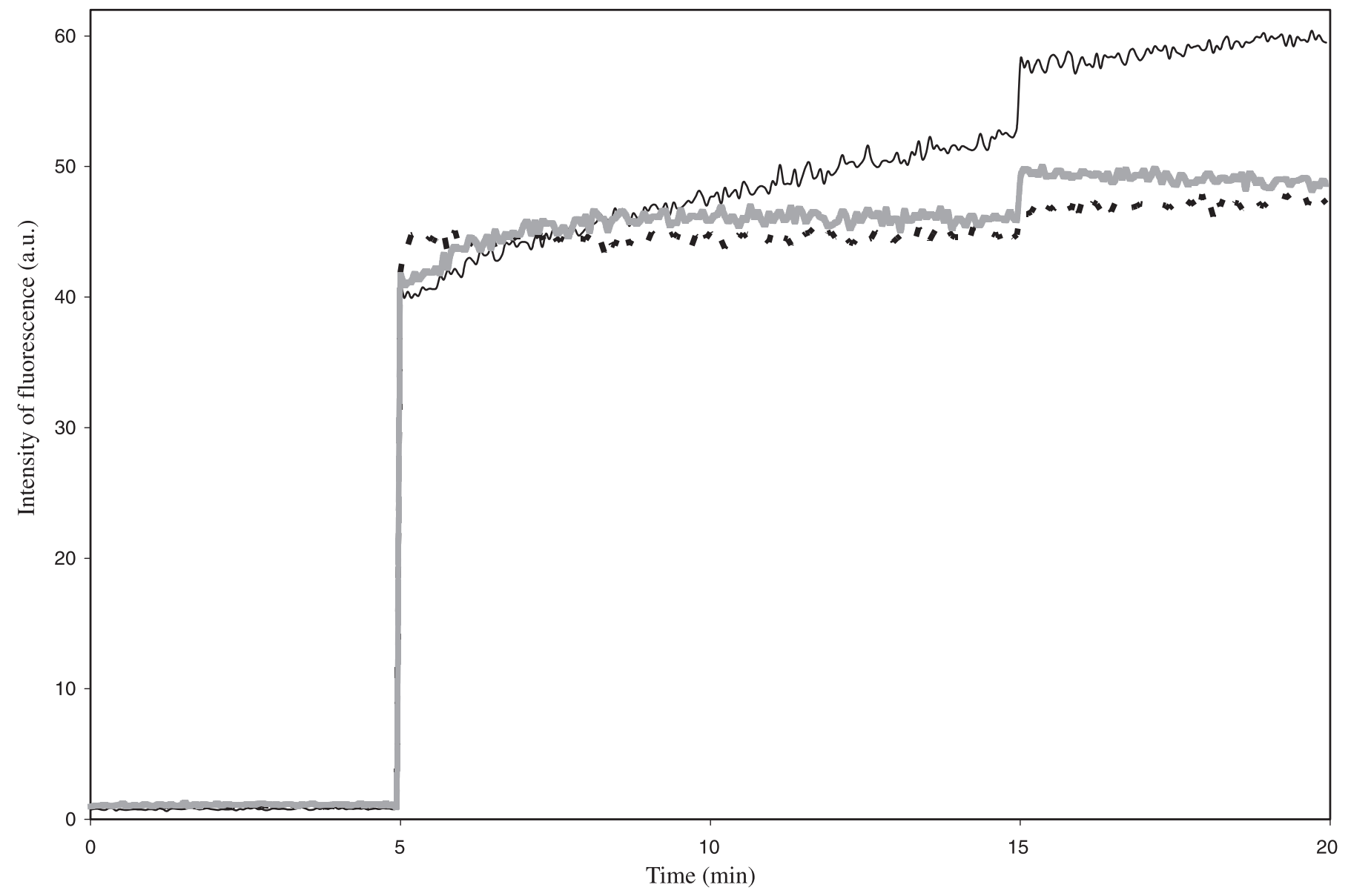

bated overnight (16-18 h). Ten millilitres of fresh MRS+C was inoculated $(2 \%)$ with this overnight culture on the following morning. The optical density (OD) of each culture was determined at $600 \mathrm{~nm}$ using a Kontron spectrophotometer (Tegimenta AG, Rotkreuz, Switzerland). When an $\mathrm{OD}_{600}$ of $0.5 \pm 0.1$ was reached, $8 \mathrm{~mL}$ of the culture was centrifuged at $7000 \mathrm{r} / \mathrm{min}(1 \mathrm{r}=2 \pi \mathrm{rad} ; 6800 \mathrm{~g})$ for $2 \mathrm{~min}$. Cells were washed twice with $2 \mathrm{~mL}$ of $50 \mathrm{mmol} \mathrm{L}^{-1}$ potassium phosphate buffer containing $2 \mathrm{mmol} \mathrm{L}^{-1} \mathrm{MgSO}_{4}$ and $2 \mathrm{mmol} \mathrm{L}^{-1}$ glucose $(\mathrm{pH} 7)$, and the pellet was resuspended in $0.5 \mathrm{~mL}$ of the same buffer. The volume of this suspension necessary to obtain a final $\mathrm{OD}_{600}$ of 0.5 was added to $2 \mathrm{~mL}$ of the buffer solution prior to the measurement of fluorescence. Three independent cultures were assayed for each strain.

\section{Fluorescence spectroscopy}

The fluorescence spectra of the bacterial samples were obtained using a Cary Eclipse fluorescence spectrophotometer (Varian, Sydney, Australia) equipped with a thermostatcontrolled, right-angled, single cuvette holder. Samples $(2 \mathrm{~mL})$ were placed in a Teflon ${ }^{\circledR}$ cuvette and the kinetics of tetracycline uptake measured over $20 \mathrm{~min}\left(\lambda_{\text {Exc }}=400 \mathrm{~nm}, \lambda_{\text {Emi }}=\right.$ $524 \mathrm{~nm}$, slit width $=5 \mathrm{~nm}$ ) at $37{ }^{\circ} \mathrm{C}$. After a time period of 5 min of preincubation $\left(t_{5 \min }\right), 100 \mu \mathrm{g} \mathrm{mL} \mathrm{m}^{-1}$ of tetracycline was added and incubation allowed to proceed for $10 \mathrm{~min}$ $\left(t_{5 \min }-t_{15 \mathrm{~min}}\right) ; 20 \mathrm{mmol} \mathrm{L}-1$ of glucose was finally added to energize the cells, and fluorescence was monitored for a further $5 \min \left(t_{15 \min }-t_{20 \min }\right)$.

\section{Mathematical analysis of data}

The spectral data were analyzed using XLStat pro 7.5 software (Addinsoft, Paris, France). Pearson principal component analysis (normed PCA) was performed to transform the large number of potentially correlated factors into a smaller number of uncorrelated factors (i.e., principal components) and thus reduce the size of the data set. This multivariate treatment allows score plots of the samples to be drawn representing the spectral patterns (Bertrand and Scotter 1992; Jollife 1986). Neighboring points on these score plots represent similar spectra.

The linearly independent principal components resulting from PCA were subjected to factorial discriminant analysis (FDA) by examining the spectral fluorescence data. The aim of this technique is to predict the likely belonging of an observation (spectrum data) to a previously defined qualitative group (Safar et al. 1994). Since the raw spectral data could not be used because of the strong correlations among variables (the measurement times), the uncorrelated principal component resulting from PCA was employed. 
Fig. 2. Discriminant analysis similarity map determined with discriminant factors 1 and 2 for the spectral data of the different tetracycline resistance groups: $\square$, resistant strains ( $\mathrm{MIC} \geq 32 \mu \mathrm{g} \mathrm{mL}^{-1}$ ); $\triangle$, semi-resistant strains $\left(1 \mu \mathrm{g} \mathrm{mL} \mathrm{m}^{-1} \leq \mathrm{MIC}<32 \mu \mathrm{g} \mathrm{mL}-1\right.$ ); $\bigcirc$, susceptible strains (MIC $<1 \mu \mathrm{g} \mathrm{mL}^{-1}$ ).

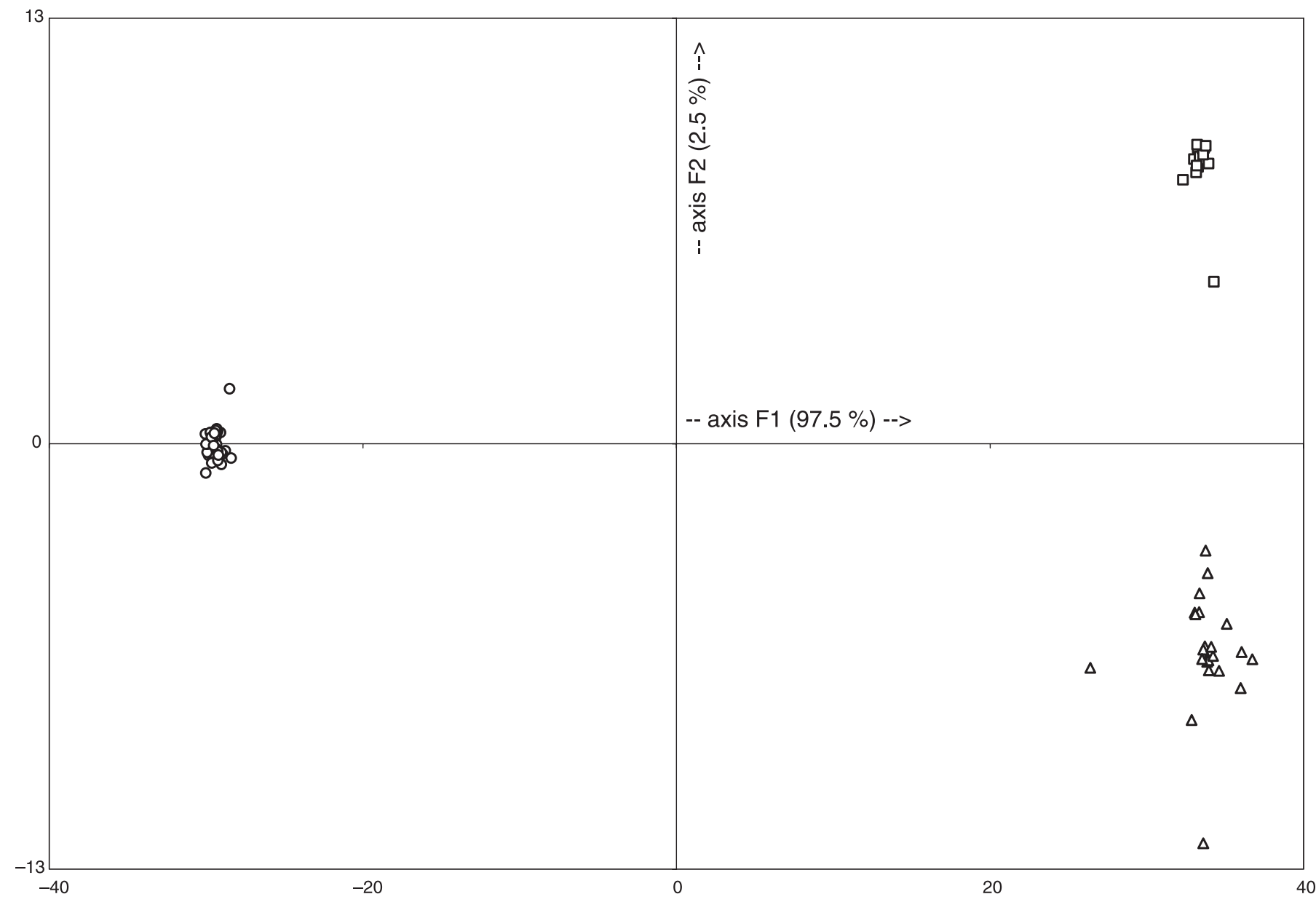

\section{Results and discussion}

\section{MICs of tetracycline}

Table 1 shows the MICs of tetracycline for the different strains. The results obtained agree well with those reported by Delgado et al. (2005). Differences with respect to the results of the latter authors were always less than two $\log _{2}$ dilutions, which is normal for MICs obtained by the microdilution method (Delgado et al. 2005; Flórez and Mayo 2005).

A tetracycline resistance gene $(\operatorname{tet}(\mathrm{W}))$ was detected in all the semi-resistant and resistant isolates (Flórez and Mayo 2005). In fact, it has been reported in several B. longum strains (Moubareck et al. 2005; Scott et al. 2000) and seems to be the most common tetracycline resistance gene in other intestinal bacterial genera (Scott et al. 2000; Roberts 2005).

\section{Fluorescence spectroscopy}

\section{Tetracycline uptake kinetics}

Figure 1 shows the spectra recorded for three representative isolates of the different susceptibility groups. In general, no correlation was found among fluorescence intensity and tetracycline resistance. However, the resistant strains reached fluorescence equilibrium soon after the addition of the antibiotic, preceded by a peak of antibiotic uptake. Resistant strains were also characterized by a small increase in uptake after the cells received glucose. In contrast, susceptible strains reached the equilibrium more slowly after the addition of tetracycline and were characterized by a greater increase in uptake after the addition of glucose.

Previous studies have shown that the movement of tetracycline across the plasma membrane is an energy-dependent process driven by the $\Delta \mathrm{pH}$ component of proton motive force (Nikaido and Thanassi 1993). The influx of the antibiotic is fast enough for fluorescence equilibrium to be reached in just a few seconds. In contrast, when ribosome-binding proteins are present (which form stable complexes with ribosomes; Spahn et al. (2001)), fluorescence equilibrium is reached much later because the binding of the tetracycline to the 30S subunit is inhibited (Nonaka et al. 2005). Based on the present observations and given that all resistant strains harbor the tet $(\mathrm{W})$ gene (encoding a ribosomal protection protein), the fluorescence equilibrium may be affected by the efficiency of the binding of the antibiotic to the ribosome. Since ribosomal binding sites are protected in resistant strains, tetracycline cannot bind to them, and the equilibrium between the internalized tetracycline and the out- 
Table 2. Classification, membership probability, supplementary observation scores, and squared distances to group centroids.

\begin{tabular}{|c|c|c|c|c|c|c|c|c|c|}
\hline \multirow[b]{2}{*}{$\begin{array}{l}\text { Test } \\
\text { strain* }\end{array}$} & \multirow[b]{2}{*}{ Group } & \multicolumn{3}{|c|}{ Probability } & \multirow[b]{2}{*}{ Factor 1} & \multirow[b]{2}{*}{ Factor 2} & \multicolumn{3}{|l|}{$D^{2}$} \\
\hline & & $\mathrm{R}$ & $\mathrm{S}$ & SR & & & $\begin{array}{l}i \text {, Centroid } \\
\text { (R) }\end{array}$ & $\begin{array}{l}i \text {, Centroid } \\
(\mathrm{S})\end{array}$ & $\begin{array}{l}i, \text { Centroid } \\
(\mathrm{SR})\end{array}$ \\
\hline M21-2 & $\mathrm{S}$ & 0 & 1 & 0 & -15.89 & -5.82 & 2842.91 & 422.13 & 2671.67 \\
\hline M21-3 & SR & 0 & 0 & 1 & 6.92 & -12.95 & 1321.26 & 1645.61 & 922.49 \\
\hline C51-1 & S & 0 & 1 & 0 & -16.81 & 3.70 & 2640.45 & 266.26 & 2752.63 \\
\hline C71-1 & $\mathrm{S}$ & 0 & 1 & 0 & -14.66 & 5.73 & 2487.67 & 418.82 & 2658.87 \\
\hline C71-2 & $\mathrm{S}$ & 0 & 1 & 0 & -49.45 & -3.70 & 7137.06 & 533.65 & 7051.74 \\
\hline C71-3 & SR & 0 & 0 & 1 & 90.86 & -4.54 & 3602.09 & 14621.20 & 3395.78 \\
\hline L43-1 & $\mathrm{S}$ & 0 & 1 & 0 & -14.29 & -4.29 & 2531.58 & 337.38 & 2404.76 \\
\hline L43-2 & $\mathrm{S}$ & 0 & 1 & 0 & -34.62 & -1.05 & 4864.23 & 170.38 & 4847.60 \\
\hline
\end{tabular}

Note: S, susceptible; SR, semi-resistant; R, resistant.

*The numbers 1,2 , and 3 refer to distinct replicate observations for every test strain.

Fig. 3. Discriminant analysis similarity map of principal (constructed model) and supplementary (test strains) data determined with discriminant factors 1 and 2 for the spectral data of the different tetracycline resistance groups: $\square$, resistant strains, principal observations (MIC $\left.\geq 32 \mu \mathrm{g} \mathrm{mL}^{-1}\right) ; \triangle$, semi-resistant strains, principal observations $\left(1 \mu \mathrm{g} \mathrm{mL}^{-1} \leq \mathrm{MIC}<32 \mu \mathrm{g} \mathrm{mL}^{-1}\right.$ ); $\boldsymbol{\Delta}$, semi-resistant strains, supplementary observations; $\bigcirc$, susceptible strains, principal observations $\left(\mathrm{MIC}<1 \mu \mathrm{g} \mathrm{mL} \mathrm{m}^{-1}\right) \boldsymbol{\bullet}$, susceptible strains, supplementary observations.

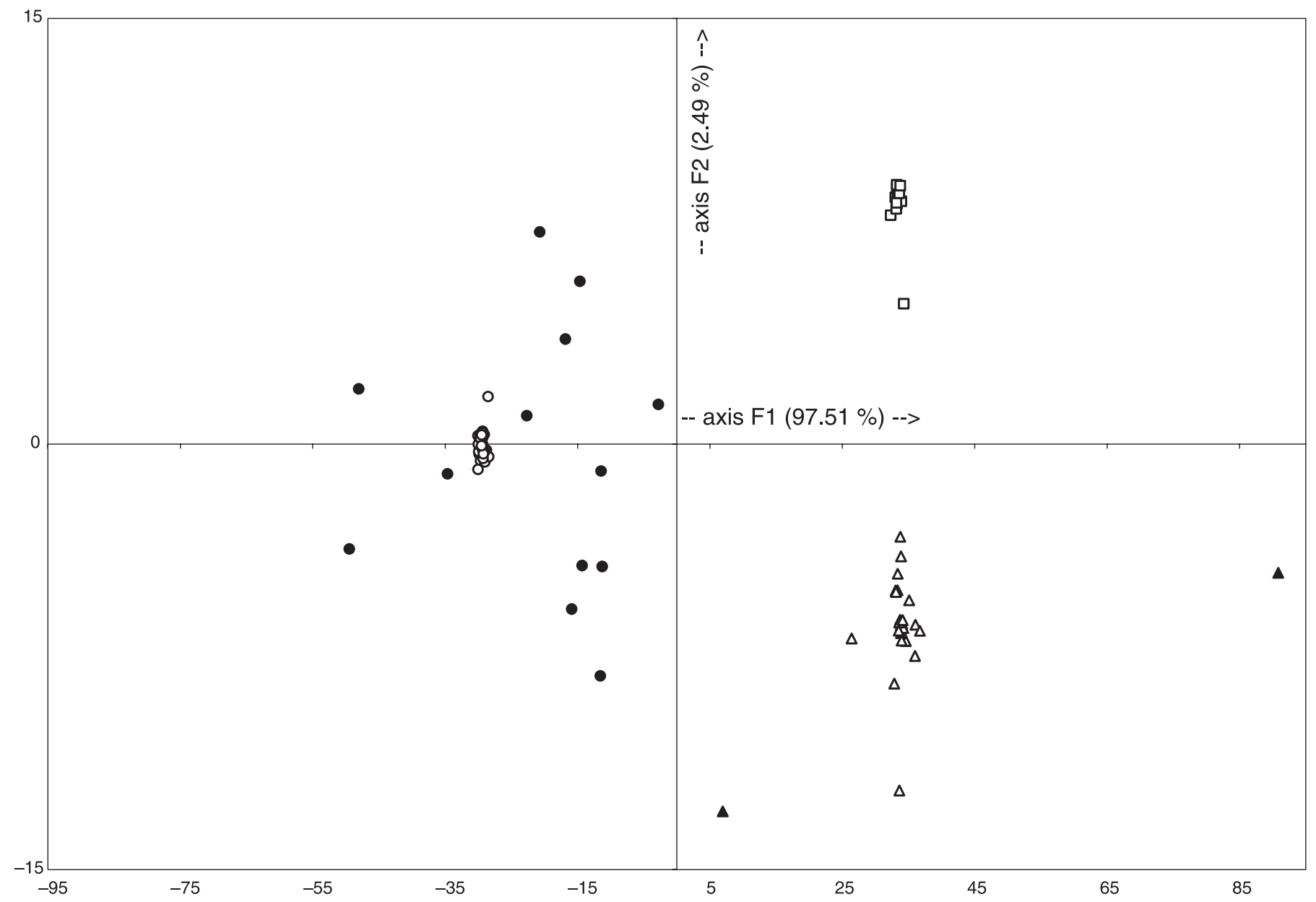


side pool is quickly reached. In contrast, in the susceptible strains, tetracycline binds to the ribosome and fluorescence equilibrium is reached later (Fig. 1: see $t_{5 \min }-t_{15 \mathrm{~min}}$ ).

Tetracycline uptake was also found to be positively correlated to the amount of $\mathrm{MgSO}_{4}$ in the buffer. In fact, fluorescence in the presence of $2 \mathrm{mmol} \mathrm{L}^{-1}$ of $\mathrm{MgSO}_{4}$ was approximately 5 -fold greater than in the presence of $0.4 \mathrm{mmol} \mathrm{L}{ }^{-1} \mathrm{MgSO}_{4}$. This agrees with previous observations suggesting that the complexion of tetracycline with divalent metal ions, such as $\mathrm{Mg}^{2+}$ or $\mathrm{Ca}^{2+}$, greatly increases fluorescence (Schneider et al. 2003).

\section{Model building}

To ensure robustness, the model was constructed using the results for 30 strains and validated with five test strains. The spectral kinetics data obtained for the 30 B. longum strains were pooled in one matrix and the data examined by PCA. The linear independent factors resulting from the PCA were then used as new variables to perform FDA based on the defined group constituting the dependent variable.

In a first step, the dependent variable was composed of 30 groups representing the number of considered strains. The aim was to ensure that the results of the three replicate assays for each strain were attributed to the group formed by the corresponding strain, thus confirming the reproducibility of the method. The confusion matrix resulting from the FDA provided $100 \%$ correct classification of the results to the corresponding strain. The first two discriminant factors were able to explain more than $86.7 \%$ of the total variance (results not shown), thus confirming reproducibility.

In a second step, the dependent variable was composed of three groups according to the resistance level: susceptible (MICs $\leq 1 \mu \mathrm{g} \mathrm{mL}{ }^{-1}$ ), semi-resistant (MICs between 1 and $32 \mu \mathrm{g} \mathrm{mL}^{-1}$ ), and resistant (MICs $\geq 32 \mu \mathrm{g} \mathrm{mL}^{-1}$ ). The confusion matrix of the FDA results indicated $100 \%$ correct classification of the strains in these groups (results not shown). Figure 2 shows the map defined by discriminant factors 1 and 2; these two factors explained $100 \%$ of the total variance. The model was therefore considered well constructed; validation experiments were therefore performed.

\section{Model validation}

The spectral kinetics data for the five test strains were collected and pooled in a matrix. PCA was then applied to a model and validating data matrices. The model matrix provided the principal observations and the validating matrix provided the supplementary observations; thus, the supplementary observations did not contribute to the inertia of the model. The linearly independent factors (principal and supplementary data) were used as new variables (principal and supplementary data) in FDA analysis. Although, 2 of the 15 observations corresponding to these supplementary observations were misclassified (Table 2), all five test strains were assigned a position close to other strains of their phenotypic group (Table 1). Both misclassified observations corresponded to the semi-resistant group (Fig. 3), but they did not invalidate the overall results. This misclassification might be explained by the small number of strains used in the construction of the model. However, since more data can be added to the model, the analysis of new B. longum strains showing differences in tetracycline resistance should certainly increase its robustness.

\section{Conclusions}

The results show that fluorescence spectroscopy is a rapid and accurate method for screening B. longum strains for resistance to tetracycline. Models similar to that constructed for B. longum could easily be developed for other bacterial species. The method is amenable to semi-complete or complete automation; this should be useful in large-scale tetracycline resistance surveys, complementing or perhaps replacing the more expensive and time-consuming phenotypic assays currently used.

\section{Acknowledgements}

This work was supported by a project within the sixth Framework Program of the EU (ACE-ART, ref. 506214). M.S. Ammor was the recipient of a postdoctoral fellowship from the Secretaría de Estado de Universidades e Investigación, Spanish Ministry of Education and Science (ref. SB2004-0165).

\section{References}

Bertrand, D., and Scotter, C.N.G. 1992. Application of multivariate analyses to NIR spectra of gelatinized starch. Appl. Spectrosc. 46: $1420-1425$.

Charteris, W.P., Kelly, P.M., Morelli, L., and Collins, J.K. 1998. Antibiotic susceptibility of potentially probiotic Bifidobacterium isolates from the human gastrointestinal tract. Lett. Appl. Microbiol. 26: 333-337.

Charteris, W.P., Kelly, P.M., Morelli, L., and Collins, J.K. 2001. Gradient diffusion antibiotic susceptibility testing of potentially probiotic lactobacilli. J. Food Prot. 64: 2007-2014.

Chopra, I., and Roberts, M. 2001. Tetracycline antibiotics: mode of action, applications, molecular biology, and epidemiology of bacterial resistance. Microbiol. Mol. Biol. Rev. 65: 232-260.

Delgado, S., Florez, A.B., and Mayo, B. 2005. Antibiotic susceptibility of Lactobacillus and Bifidobacterium species from the human gastrointestinal tract. Curr. Microbiol. 50: 202-207.

European Commission. 2001. Opinion of the Scientific Committee on Animal Nutrition on the criteria for assessing the safety of micro-organisms resistant to antibiotics of human clinical and veterinary importance [online]. Available from http://www.europa. eu.int/comm/food/fs/sc/scan/out64_en.pdf [cited 18 April 2001].

Flórez, A.B., and Mayo, B. 2005. Tetracycline resistance genes from Bifidobacterium species of human origin. Proceedings of the 3rd International Meeting on Probiotics, Prebiotics and New Foods. Università Urbaniana, 4-6 September, 2005, Rome, Italy.

Jollife, I.T. 1986. Principal component analysis. Springer, New York.

Lacroix, J.M., and Walker, C.B. 1995. Detection and incidence of the tetracycline resistance determinant tet $(\mathrm{M})$ in the microflora associated with adult periodontitis. J. Periodontol. 66: 102-108.

Lim, K.S., Huh, C.S., and Baek, Y.J. 1993. Antimicrobial susceptibility of bifidobacteria. J. Dairy Sci. 76: 2168-2174.

Matteuzzi, D., Crociani, F., and Brigidi, P. 1983. Antimicrobial susceptibility of Bifidobacterium. Ann. Microbiol. (Paris), 134: 339-349. 
Moubareck, C., Gavini, F., Vaugien, L., Butel, M.J., and DoucetPopulaire, F. 2005. Antimicrobial susceptibility of bifidobacteria. J. Antimicrob. Chemother. 55: 38-44.

Nikaido, H., and Thanassi, D.G. 1993. Penetration of lipophilic agents with multiple protonation sites into bacterial cells: tetracyclines and fluoroquinolones as examples. Antimicrob. Agents Chemother. 37: 1393-1399.

Nonaka, L., Connell, S.R., and Taylor, D.E. 2005. 16S rRNA mutations that confer tetracycline resistance in Helicobacter pylori decrease drug binding in Escherichia coli ribosomes. J. Bacteriol. 187: 3708-3712.

O'Sullivan, D.J. 2001. Screening of intestinal microflora for effective probiotic bacteria. J. Agric. Food Chem. 49: 1751-1760.

Ouwehand, A.C., Salminen, S., and Isolauri, E. 2002. Probiotics: an overview of beneficial effects. Antonie Leeuwenhoek, 82: 279-289.

Roberts, M.C. 2005. Update on acquired tetracycline resistance genes. FEMS Microbiol. Lett. 245: 195-203.

Safar, M., Bertrand, D., Robert, P., Devaux, M.F., and Genot, C. 1994. Characterization of edible oils, butters and margarines by fourier transform infrared spectroscopy with attenuated total reflectance. J. Am. Oil Chem. Soc. 71: 371-377.
Schneider, S., Schmitt, M.O., Brehm, G., Reiher, M., Matousek, P., and Towrie, M. 2003. Fluorescence kinetics of aqueous solutions of tetracycline and its complexes with $\mathrm{Mg}^{2+}$ and $\mathrm{Ca}^{2+}$. Photochem. Photobiol. Sci. 2: 1107-1117.

Scott, K.P., Melville, C.M., Barbosa, T.M., and Flint, H.J. 2000. Occurrence of the new tetracycline resistance gene tet $(\mathrm{W})$ in bacteria from the human gut. Antimicrob. Agents Chemother. 44: 775-777.

Spahn, C.M., Blaha, G., Agrawal, R.K., Penczek, P., Grassucci, R.A., Trieber, C.A., Connell, S.R., Taylor, D.E., Nierhaus, K.H., and Frank, J. 2001. Localization of the ribosomal protection protein $\operatorname{Tet}(\mathrm{O})$ on the ribosome and the mechanism of tetracycline resistance. Mol. Cell, 7: 1037-1045.

Tuohy, K.M., Probert, H.M., Smejkal, C.W., and Gibson, G.R. 2003. Using probiotics and prebiotics to improve gut health. Drug Discov. Today, 8: 692-700.

Ventura, M., van Sinderen, D., Fitzgerald, G.F., and Zink, R. 2004. Insights into the taxonomy, genetics and physiology of bifidobacteria. Antonie Leeuwenhoek, 86: 205-223.

Wegener, H.C. 2003. Antibiotics in animal feed and their role in resistance development. Curr. Opin. Microbiol. 6: 439-445. 